\title{
Evaluation of kininogen 1, osteopontin and $\alpha$-1-antitrypsin in plasma, bronchoalveolar lavage fluid and urine for lung squamous cell carcinoma diagnosis
}

\author{
WEIWEI WANG ${ }^{1}$, SHANSHAN WANG $^{1}$ and MAN ZHANG ${ }^{2,3}$
}

\begin{abstract}
Departments of ${ }^{1}$ Pulmonary and Critical Care Medicine, ${ }^{2}$ Clinical Laboratory Medicine, Beijing Shijitan Hospital, Capital Medical University; ${ }^{3}$ Beijing Key Laboratory of Urinary Cellular Molecular Diagnostics, Department of Clinical Laboratory Medicine, Beijing Shijitan Hospital, Capital Medical University, Beijing 100038, P.R. China
\end{abstract}

Received July 24, 2019; Accepted January 14, 2020

DOI: $10.3892 / \mathrm{ol} .2020 .11376$

\begin{abstract}
Lung squamous cell carcinoma (LUSC) progression is accompanied by changes in protein levels that may be reflected in body fluids, such as plasma, bronchoalveolar lavage fluid (BALF) and urine. Certain proteins present in these biofluids can facilitate lung cancer diagnosis. Kininogen 1 (KNG1), osteopontin (OPN) and $\alpha$-1-antitrypsin (AAT) are associated with tumorigenesis. The present study aimed to explore the combined monitoring of plasma, urine and BALF to gain insight into LUSC by monitoring the levels of the above three protein using ELISA. LUSC $(n=31)$ and healthy controls with benign lung diseases $(n=20)$ were enrolled in the study. KNG1 levels in plasma, BALF and urine were significantly higher in patients with LUSC patients than in controls $(\mathrm{P}<0.0001, \mathrm{P}<0.0001$ and $\mathrm{P}=0.0010$, respectively). OPN was upregulated in the plasma and BALF of patients with LUSC relative to controls $(\mathrm{P}=0.0107$ and $\mathrm{P}=0.0004$, respectively), whereas its levels in the urine of healthy controls were significantly higher $(\mathrm{P}=0.0088)$. Patients with LUSC had higher AAT levels in plasma, BALF and urine compared with those of the controls $(\mathrm{P}=0.0022, \mathrm{P}=0.0014$ and $\mathrm{P}=0.0005$, respectively). Receiver operating characteristic analysis showed an area under the curve (AUC) of 0.81 for KNG1 in plasma, 0.91 in BALF and 0.81 in urine. The AUC for OPN was 0.71 in plasma, 0.83 in BALF and 0.75 in urine. The AUC for AAT was 0.74 in plasma, 0.74 in BALF and 0.86 in urine. Immunohistochemical staining in 20 paired LUSC and adjacent normal tissues showed that KNG1, OPN and AAT levels were higher in LUSC tissues. Therefore, our results showed that KNG1, OPN and AAT in biofluids might be useful for the
\end{abstract}

Correspondence to: Dr Man Zhang, Department of Clinical Laboratory Medicine, Beijing Shijitan Hospital, Capital Medical University, 10 Tieyi Road, Haidian, Beijing 100038, P.R. China E-mail: zhangman@bjsjth.cn

Key words: biomarker, lung squamous cell carcinoma, urine, bronchoalveolar lavage fluid diagnosis of LUSC. These markers in urine and BALF may be better than in plasma for detecting LUSC.

\section{Introduction}

Lung cancer is the leading cause of cancer death in the world, accounting for $>1 / 4$ of all cancer-related deaths (1). Almost $85 \%$ of patients with lung carcinoma exhibit non-small cell lung cancer (NSCLC), of which lung squamous cell carcinoma (LUSC) accounts for $\sim 30 \%$ and results in $\sim 400,000$ deaths annually (2). The primary strategy for LUSC treatment at present remains surgical resection. However, this treatment is generally not effective once the disease progresses to a metastatic stage. Individuals with advanced disease have a poor prognosis. Indeed, chemotherapy generally fails to treat patients with metastatic LUSC, and this disease has a $<20 \%$ 5 -year survival rate, with no optimal targeted therapeutic having yet been identified to treat this disease (1). The low survival rate of patients with LUSC is at least partially attributable to the disease often not being diagnosed until it is relatively advanced, thus precluding surgical treatment (2). The present study aims to provide a useful reference in the future diagnosis of LUSC.

Cancer cells and normal cells exhibit distinct patterns of protein production and secretion, with numerous tumors exhibiting marked shifts in proteolytic activity as their signaling alters during the progression towards malignant disease (3). As such, it is possible to detect specific cancer-associated proteins in the biofluids of patients, and these proteins as biomarkers can offer an insight into disease type and stage. Such biomarkers have been sought as a means of facilitating LUSC diagnosis and monitoring, since their detection is easier than a more invasive biopsy procedure and allow rapid screening. Minimally invasive tumor biomarkers that are readily accessible in biofluids such as plasma, urine and bronchoalveolar lavage fluid (BALF) would thus offer a means of easily and effectively differentiating between patients with cancer and those with benign disease (4-6). Urine markers can be detected without exposing individuals to any risk, and urine is highly amenable to large-scale screening efforts. Therefore, urine is a particularly promising biospecimen for biomarker screening. 
In theory, such an approach would allow population-level screening of individuals, thereby facilitating the early detection of LUSC and other types of cancer. However, the current biomarkers for the diagnosis of LUSC are mainly blood tumor markers such as squamous cell carcinoma (SCC) antigen and cytokeratin 19 fragment 21-1, but their sensitivity and specificity are low. There arw few studies on biomarkers of LUSC in easily accessible specimens, such as urine and BALF $(4,5)$.

Kininogen 1 (KNG1) is a cysteine proteinase inhibitor known to inhibit endothelial cell proliferation and angiogenesis (7). Certain groups have reported the detection of KNG1 using mass spectrometry, and recently KNG1 has been identified as a serum biomarker for advanced colorectal adenoma and colorectal cancer, in addition to being a salivary biomarker useful for oral SCC detection and for the monitoring of high-risk individuals $(8,9)$. However, the disease relevance of KNG1 levels in patients with LUSC remains to be assessed. Osteopontin (OPN) is expressed in a variety of tissues, and is abundant in body fluids such as blood, milk and urine (10). It is a multifunctional phosphorylated glycoprotein involved in cell migration and adhesion, and mediates the invasion and metastasis of tumor cells (6). OPN is associated with tumorigenesis, progression, metastasis and cancer prognosis (11). $\alpha$-1-Antitrypsin (AAT) is also known as serine proteinase inhibitor A1. It was reported that the level of AAT was elevated in the tissues and serum of patients with lung cancer, wherein it was thought to promote tumor invasion and metastasis (12-14). At present, the levels of OPN and AAT in the urine and BALF of patients with lung cancer remain unclear. Moreover, the combined assessment of the diagnostic relevance of KNG1, OPN and AAT levels in urine, BALF and plasma have not been studied in LUSC thus far.

The present study aimed to assess whether KNG1, OPN, and AAT levels in specific biofluids, as measured by ELISA, may be a viable diagnostic biomarker for LUSC. In addition, the levels of these three proteins in LUSC tissues were assessed via immunohistochemistry (IHC).

\section{Materials and methods}

Study subjects. Patients with LUSC patients and controls were recruited from Beijing Shijitan Hospital between October 2014 and March 2017. The Ethics Committee of Beijing Shijitan Hospital, Capital Medical University approved the present study (approval no. 10, 2014). All study participants provided written informed consent, and the study was performed according to the Declaration of Helsinki. For patients with LUSC, two senior pathologists confirmed the diagnosis based on pathology findings. The control group included various benign lung disorders such as chronic cough, benign pulmonary nodules, hemoptysis, bronchitis, sarcoidosis, asthma, bronchiectasis and tuberculosis. The characteristics of the patients with LUSC and the control subjects are presented in Table I. All plasma, BALF and urine samples were collected prior to radiological, surgical or chemotherapeutic treatment. There was no evidence of hematuresis in any urine samples, with all albumin/creatinine ratios in urine samples being $<30 \mathrm{mg} / \mathrm{g}$. From 20 of the total number of patients in this study, pairs of LUSC tumor tissue and adjacent normal tissue located $\geq 5 \mathrm{~cm}$ from the tumor site were also used. Patients who underwent preoperative radio- or chemo-therapeutic treatment were excluded from the study. Patients with LUSC were classified based on the 2009 TNM classification system for malignant tumor staging produced by the International Union Against Cancer and the American Joint Committee on Cancer.

Plasma collection. From each subject, $6 \mathrm{ml}$ of venous blood was collected using closed syringes containing a coagulation activator, and samples were then immediately centrifuged at $3,600 \mathrm{x} \mathrm{g}$ for $10 \mathrm{~min}$. The plasma fraction was transferred to a separate Eppendorf tube and stored at $-80^{\circ} \mathrm{C}$. Of note, subjects were fasting at the time of sample collection.

Urine collection. A total of $50 \mathrm{ml}$ of mid-stream urine from each subject was collected into a sterile polypropylene tube. Samples were immediately centrifuged at $400 \mathrm{x}$ g for $15 \mathrm{~min}$, and the supernatant was then aliquoted and frozen at $-80^{\circ} \mathrm{C}$.

$B A L F$ collection. Patients were first administered $2 \%$ lidocaine for local anesthesia. Subsequently, a fiber-optic bronchoscope (Olympus EXERA BF 240; Olympus Corporation) was used to perform a bronchoscopy. Lavage was conducted before biopsy or brushing-based specimen collection to prevent any possibility of blood contamination. Lavage was performed by washing the bronchus of the side affected by the disease twice with $50 \mathrm{ml}$ sterile saline solution, and then slowly withdrawing this solution into a siliconized tube and placing it in ice water. A recovered BALF volume of $40 \mathrm{ml}$ was considered acceptable. After isolation, debris and cells were immediately removed via centrifugation at $1,500 \times \mathrm{g}$ for $10 \mathrm{~min}$, and the supernatants were subsequently frozen at $-80^{\circ} \mathrm{C}$.

ELISA. The KNG1, OPN and AAT levels in plasma, urine and BALF were measured using a commercially available ELISA kit Abnova, Abcam and Abcam, respectively, according to the manufacturer's instructions. Plasma and BALF samples were diluted 200- and 100-fold, respectively. Next, plasma, BALF and urine samples were incubated in KNG1 ELISA plates. Urine samples were diluted 1,500-fold and then plasma, BALF and urine samples were incubated in OPN ELISA plates. The AAT ELISA plates were incubated with plasma, urine and BALF samples at dilutions of 1:400,000, 1:400 and 1:500, respectively. The optical density was measured at $450 \mathrm{~nm}$ with a Model 680 microplate reader (Bio-Rad Laboratories, Inc.). A standard curve was drawn for each plate using the concentration of the standard sample and the corresponding optical density value of each well. Both positive and negative controls were used for validation.

$I H C$. Following surgical collection, LUSC and adjacent healthy tissue samples were formalin-fixed, paraffin-embedded and cut into 4-mm sections. Next, xylene was used to deparaffinize the samples for $20 \mathrm{~min}$, and an ethanol gradient (100, 100, 95 and $75 \%, 2 \mathrm{~min}$ each) was then used to dehydrate samples. PBS was next used to wash the samples (5 times, 10 min each), and the samples were then heated under pressure with an antigen unmasking reagent to facilitate antigen retrieval. After an additional 10-min wash with $\mathrm{PBS}, 3 \% \mathrm{H}_{2} \mathrm{O}_{2}$ was used to treat the samples for $15 \mathrm{~min}$, followed by an additional wash 
Table I. Demographics of patients with cancer and control subjects.

\begin{tabular}{|c|c|c|c|c|}
\hline \multirow[b]{2}{*}{ Characteristics } & \multicolumn{2}{|c|}{ Biofluids set } & \multicolumn{2}{|c|}{ Tissue set } \\
\hline & $\begin{array}{l}\text { Patients with cancer } \\
\qquad(\mathrm{n}=31)\end{array}$ & $\begin{array}{l}\text { Normal controls } \\
\qquad(n=20)\end{array}$ & P-value & $\begin{array}{c}\text { Tumor/adjacent normal } \\
\text { pairs }(n=20)\end{array}$ \\
\hline Age, years & $65.7 \pm 9.7$ & $67.4 \pm 9.4$ & 0.55 & $63.0 \pm 8.2$ \\
\hline \multicolumn{5}{|l|}{ Sex } \\
\hline Female & $10(32 \%)$ & $8(40 \%)$ & 0.57 & $6(30 \%)$ \\
\hline Male & $21(68 \%)$ & $12(60 \%)$ & & $14(70 \%)$ \\
\hline \multicolumn{5}{|l|}{ Smoking habit } \\
\hline Nonsmoker & $11(35 \%)$ & $10(50 \%)$ & 0.30 & $8(40 \%)$ \\
\hline Ever smoker & $20(65 \%)$ & $10(50 \%)$ & & $12(60 \%)$ \\
\hline \multicolumn{5}{|l|}{ Clinical stage } \\
\hline I-II & 13 & & & 9 \\
\hline III-IV & 18 & & & 11 \\
\hline \multicolumn{5}{|l|}{ Pleural invasion } \\
\hline Absent & 27 & & & 20 \\
\hline Present & 4 & & & 0 \\
\hline \multicolumn{5}{|c|}{ Lymphatic invasion } \\
\hline Positive & 25 & & & 15 \\
\hline Negative & 6 & & & 5 \\
\hline
\end{tabular}

step. Tissues were then probed overnight at $4^{\circ} \mathrm{C}$ with appropriate primary antibodies against OPN (1:300, Abcam), AAT (1:300, Abcam) and KNG1 (1:200, Abnova). Samples were again washed and then probed for $20 \mathrm{~min}$ with a secondary antibody conjugated to HRP (Beijing Zhongshan Jinqiao Biotechnology, Co., Ltd.) at $37^{\circ} \mathrm{C}$ the following day. An additional 15-min wash was then performed, and the chromogenic 3,3'-diaminobenzidine mixture(Beijing Zhongshan Jinqiao Biotechnology, Co. Ltd.) was next used to stain the samples for $5 \mathrm{~min}$. Hematoxylin was used for counterstaining for $2 \mathrm{~min}$, and then the samples were dehydrated with ethanol $(75,95$, 100 and 100\%) and washed with xylene, and natural gum was used to seal the samples.

Two independent pathologists blinded to the patients' information independently assessed the IHC slides via light microscopy. A Nikon Ci-S (Nikon Corporation) microscope with NIS-Elements F software (Nikon Corporation) was used to capture images of the samples. Sample scoring was conducted as in previous studies based on 10 different fields of view (15). Both staining intensity (intensity) and area (extent) were scored for each sample. With respect to intensity, samples were scored as either $0,1,2$, or 3, which corresponded to no, mild, moderate, or intense staining, respectively. With respect to area, samples were scored as either $0,1,2,3$, or 4 , which corresponded to 0 , $1-10,11-50,51-80$, and $81-100 \%$ of positive cells, respectively. These two scores were multiplied together to yield an overall score, with overall scores of 4-12 being considered positive, and scores of $0-3$ being considered negative.

Statistical analysis. All statistical analyses were conducted using SPSS v22.0 (IBM Corp.). Normally distributed data were compared via Student's t-tests, while Mann-Whitney U tests was used for comparisons of non-normally distributed data. The sensitivity and specificity of these biomarkers were assessed based on the area under the curve (AUC) of the receiver operating characteristic (ROC) curve. $\chi^{2}$ test was used to assess the baseline characteristic differences between the LUSC and control groups, and to compare the proteins levels in LUSC and adjacent normal lung tissues. All tests were two-sided, and $\mathrm{P}<0.05$ was considered to indicate a statistically significant difference.

\section{Results}

ELISA. The KNG1 levels in the plasma, BALF and urine of patients with LUSC were significantly higher than those in benign controls $(\mathrm{P}<0.001)$ (Table II). The KNG1 level in BALF was significantly lower than that in plasma $(\mathrm{P}<0.0001)$, but significantly higher than that in urine $(\mathrm{P}<0.0001)$.

The OPN levels in the plasma and BALF of patients with LUSC were significantly higher than those in the controls ( $\mathrm{P}<0.05$ for both); however, the OPN level in urine tended to be lower in patients with LUSC than that in controls $(\mathrm{P}<0.05)$ (Table II). The OPN level in plasma was significantly higher than that in BALF and urine $(\mathrm{P}<0.001$ for both), and there was also a significant difference in OPN level between BALF and urine $(\mathrm{P}<0.05)$. Notably, the OPN level in BALF was higher than that in urine in patients with LUSC $(\mathrm{P}<0.05)$, but lower than that in urine in the controls $(\mathrm{P}<0.05)$.

The AAT levels in the plasma, BALF and urine of patients with LUSC were significantly higher than those in the controls $(\mathrm{P}<0.01)$ (Table II). The AAT level in BALF was significantly lower than that in plasma $(\mathrm{P}<0.0001)$ but significantly higher than that in urine $(\mathrm{P}<0.0001)$. 
Table II. Levels of OPN, AAT and KNG1 in the plasma, BAFL and urine of patients with LUSC and benign disease controls.

\begin{tabular}{|c|c|c|c|c|}
\hline Marker & Unit & LUSC & Benign & P-value \\
\hline \multicolumn{5}{|l|}{ KNG1 } \\
\hline Plasma & $\mu \mathrm{g} / \mathrm{ml}$ & $1,664.1 \pm 292.7$ & $1,310.6 \pm 265.4$ & $<0.0001$ \\
\hline BALF & $\mu \mathrm{g} / \mathrm{ml}$ & $67.3 \pm 35.9$ & $20.9 \pm 17.8$ & $<0.0001$ \\
\hline Urine & $\mu \mathrm{g} / \mathrm{ml}$ & $3.4 \pm 1.8$ & $1.3 \pm 1.5$ & 0.0010 \\
\hline \multicolumn{5}{|l|}{ OPN } \\
\hline Plasma & $\mathrm{ng} / \mathrm{ml}$ & $4,8108.2 \pm 37,757.3$ & $21,316.5 \pm 11,255.8$ & 0.0107 \\
\hline BALF & $\mathrm{ng} / \mathrm{ml}$ & $160.3 \pm 223.0$ & $32.7 \pm 47.1$ & 0.0004 \\
\hline Urine & $\mathrm{ng} / \mathrm{ml}$ & $86.1 \pm 43.2$ & $132.5 \pm 58.4$ & 0.0088 \\
\hline \multicolumn{5}{|l|}{ AAT } \\
\hline Plasma & $\mu \mathrm{g} / \mathrm{ml}$ & $25,082.7 \pm 9,145.2$ & $16,589.1 \pm 9,138.7$ & 0.0022 \\
\hline BALF & $\mathrm{ng} / \mathrm{ml}$ & $30,577.0 \pm 13,047.6$ & $16,768.7 \pm 13,427.0$ & 0.0014 \\
\hline Urine & $\mathrm{ng} / \mathrm{ml}$ & $2,176.9 \pm 1,536.9$ & $788.2 \pm 690.0$ & 0.0005 \\
\hline
\end{tabular}

The proteins level in two groups were presented as mean \pm SD. P-values were calculated by t-test (normally distributed continuous data) or Mann-Whiney U-test (non-normally distributed continuous data). $\mathrm{P}<0.05$ was considered to indicate a statistically significant difference. LUSC, lung squamous cell carcinoma; KNG1, kininogen 1; OPN, osteopontin; AAT, $\alpha$-1-antitrypsin.

ROC analysis. The AUC of the ROC curve, sensitivity and specificity values for KNG1, OPN and AAT in plasma, BALF and urine are shown in Table III. The results indicated that the combination of KNG1, OPN and AAT could improve the respective AUC values in plasma, BALF and urine (Table III).

KNG1, OPN and AAT protein expression in LUSC tissues. The results from IHC showed that KNG1, OPN, and AAT proteins were primarily expressed in the cytoplasm. The protein expression levels of KNG1, OPN and AAT were significantly increased in LUSC tissues compared with those in the controls $(\mathrm{P}<0.05)$ (Fig. 1, Table IV).

\section{Discussion}

Identification of biomarkers in various biological fluids is a promising strategy for lung cancer detection. Blood is the most studied biofluid with respect to biomarker discovery; thus, there is a wealth of information available regarding the blood proteome in multiple diseases. Considering its close association with lung tissue, BALF offers a means of assessing lung-related biomarkers, and previous BALF analysis results have shown some equivalence with biopsy findings (16). Urine is an ideal biofluid for biomarkers assessment owing to its ease of repeated noninvasive collection in large quantities. In addition, protein levels in urine tend to remain fairly stable due to low levels of proteolytic degradation.

The present study demonstrated the combined use of three biofluids (plasma, BALF, and urine) and tissues for lung cancer diagnosis purpose. To the best of our knowledge, this study is the first to describe the potential for KNG1, OPN and AAT to be used as diagnostic biomarkers of LUSC in plasma, BALF and urine specimens. The areas under the ROC curve of KNG1 in BALF was 0.91, and the AUC of KNG1 in urine was 0.81, which as good as in the plasma. The AUC of OPN in BALF was 0.83 , while the AUC of OPN in urine was 0.75 , which was better than that in plasma. The AUC of AAT in urine was 0.86 , which was better than that in plasma and BALF. These results emphasized the potential of the above markers in urine and BALF to be used as diagnostic tools.

KNG1 protein is encoded by the KNG1 gene, and is a cysteine proteinase inhibitor that plays key roles in the process of blood coagulation. In addition, KNG1 has been found to play roles in cancer development, with different expression in different tumors. For example, KNG1 levels were decreased in the serum of patients with breast cancer (17), cervical cancer (18), and endometrial cancer (18), as well as in the urine of ovarian carcinoma (19) and renal cell carcinoma (20). Moreover, KNG1 was expressed at low levels in glioma cells (21) and renal cell carcinoma tissue (22). By contrast, increased KNG1 levels have been reported in the serum of patients with hepatocellular carcinoma (23), gastric carcinoma (24) and colorectal cancer (5). IHC staining revealed KNG1 expression to be significantly higher in colorectal cancer and advanced colorectal adenoma tissues than that in normal mucosa (25). Bioinformatics analyses suggested that KNG1 might play critical roles in colorectal cancer liver metastasis (26). KNG1 levels were also upregulated in other biofluids, such as the saliva of patients with oral squamous cell carcinoma (8) and the bile of patients with cholangiocarcinoma and pancreatic cancer (27). In our study, plasma, BALF and urine KNG1 levels were significantly higher in patients with LUSC compared with those in the controls, and this was also consistent with IHC data from 20 patients, who displayed higher KNG1 protein levels in tumor tissues than in normal tissues. We hypothesized that the observed increase in KNG1 levels in the assessed biofluids of patients with LUSC was a result of cancer cell-mediated production of this protein. While its specific mechanistic function in LUSC remains uncertain, KNG1 was thought to exert anti-angiogenic and anti-endothelial cell proliferative activities in certain cancers types (18). A previous study found that aberrant ceRNA-mediated regulation 
Table III. Area under curve, sensitivity and specificity for KNG1, OPN and AAT in plasma, BALF and urine.

\begin{tabular}{|c|c|c|c|c|c|}
\hline Marker & Cut-off level & AUC & Sensitivity, $\%$ & Specificity, \% & P-value \\
\hline \multicolumn{6}{|l|}{ KNG1 } \\
\hline Plasma & $1,445.2 \mu \mathrm{g} / \mathrm{ml}$ & 0.81 & 74 & 75 & 0.0002 \\
\hline BALF & $30.0 \mu \mathrm{g} / \mathrm{ml}$ & 0.91 & 92 & 73 & $<0.0001$ \\
\hline Urine & $1.3 \mu \mathrm{g} / \mathrm{ml}$ & 0.81 & 90 & 59 & 0.0015 \\
\hline \multicolumn{6}{|l|}{ OPN } \\
\hline Plasma & $46,469.5 \mathrm{ng} / \mathrm{ml}$ & 0.71 & 45 & 100 & 0.0115 \\
\hline BALF & $40.9 \mathrm{ng} / \mathrm{ml}$ & 0.83 & 81 & 93 & 0.0008 \\
\hline Urine & $111.4 \mathrm{ng} / \mathrm{ml}$ & 0.75 & 85 & 65 & 0.0105 \\
\hline \multicolumn{6}{|l|}{ AAT } \\
\hline Plasma & $20,393.7 \mu \mathrm{g} / \mathrm{ml}$ & 0.74 & 65 & 75 & 0.0046 \\
\hline BALF & $37,621.5 \mathrm{ng} / \mathrm{ml}$ & 0.74 & 52 & 100 & 0.0020 \\
\hline Urine & $628.4 \mathrm{ng} / \mathrm{ml}$ & 0.86 & 100 & 53 & 0.0008 \\
\hline
\end{tabular}

$\mathrm{P}<0.05$ was considered to indicate a statistically significant difference. KNG1, kininogen 1; OPN, osteopontin; AAT, $\alpha-1$-antitrypsin; AUC, area under the curve.

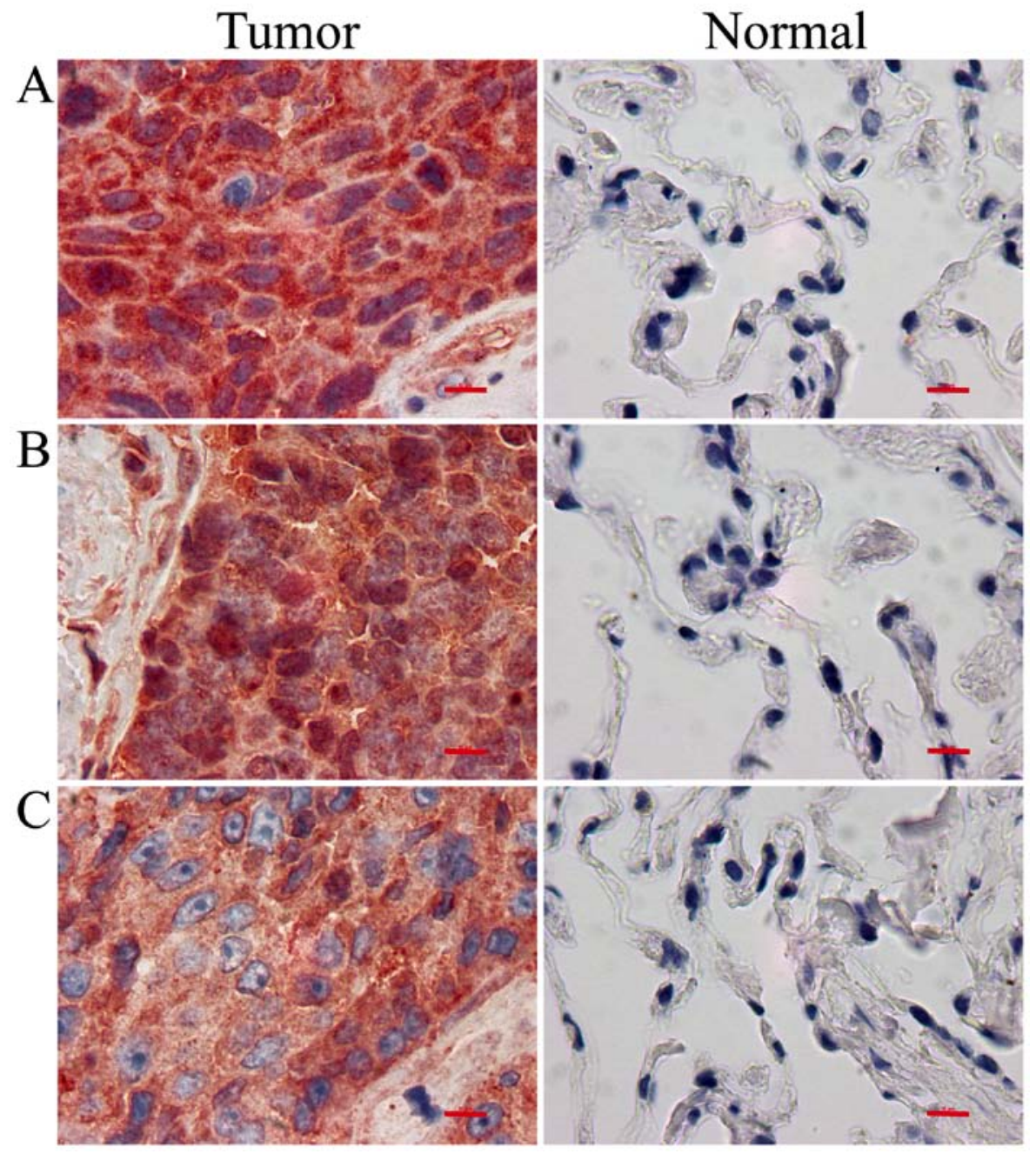

Figure 1. Expression levels of KNG1, OPN and AAT in LUSC and adjacent normal lung tissues were determined by immunohistochemistry. (A) KNG1 expression in LUSC tissues (left) and adjacent normal lung tissues (right). Positive expression of KNG1 was detected in LUSC tissue but not in the adjacent normal lung tissue. (B) OPN expression in LUSC tissues (left) and adjacent normal lung tissues (right). OPN expression was positive in LUSC tissue and negative in adjacent normal lung tissue. (C) AAT expression in LUSC tissues (left) and adjacent normal lung tissues (right). Positive expression of AAT was detected in LUSC tissue but not in the adjacent normal lung tissue. Scale bar, $10 \mu \mathrm{m}$; magnification, $\mathrm{x} 1,000$. LUSC, lung squamous cell carcinoma; BALF, bronchoalveolar lavage fluid; KNG1, kininogen 1; OPN, osteopontin; AAT, $\alpha$-1-antitrypsin. 
Table IV. Expression levels of KNG1, OPN and AAT in LUSC and adjacent normal lung tissues.

\begin{tabular}{lcccccc}
\hline & \multicolumn{2}{c}{$\begin{array}{c}\text { LUSC tissue, } \\
\mathrm{n}(\mathrm{n}=20)\end{array}$} & & \multicolumn{2}{c}{$\begin{array}{c}\text { Normal lung } \\
\text { tissue, } \mathrm{n}(\mathrm{n}=20)\end{array}$} \\
\cline { 2 - 3 } Proteins & $4-12$ & $0-3$ & & $4-12$ & $0-3$ & P-value \\
\hline KNG1 & 9 & 11 & & 18 & 0.031 \\
OPN & 8 & 12 & & 1 & 19 & 0.020 \\
AAT & 7 & 13 & & 1 & 19 & 0.044
\end{tabular}

LUSC, lung squamous cell carcinoma; KNG1, kininogen 1; OPN, osteopontin; AAT, $\alpha$-1-antitrypsin.

of KNG1 contributed to glioblastoma-induced angiogenesis, which provided potential targets for the development of novel therapeutic strategies for glioblastoma (21). Importantly, KNG1 levels in plasma, BALF, and urine might serve as a potential LUSC biomarker, although the mechanism of KNG1 in LUSC needs further study.

OPN is a protein that plays crucial roles in immunity, remodeling of tissues and malignant transformation of tumor cells. The present study observed elevated OPN expression in the tumors of patients with LUSC, which was consistent with previous findings. Indeed, one study observed a significant link between OPN levels and gender, TNM stage, tumor differentiation, and poor outcomes in patients with NSCLC $(28,29)$. OPN could play a variety of functions, binding with cluster of differentiation 44 or certain integrins to trigger the activation of the PI3K/AKT, Janus kinase 2, and focal adhesion kinase signaling pathways, thereby serving as a vital regulator of the epithelial-mesenchymal transition (30-32). Thus, OPN plays an essential role in cancer progression. OPN is a secreted protein that can be detected in different biofluids. High OPN levels in plasma were associated with higher levels of hypoxia in tumors and a higher risk of recurrence in patients with early stage NSCLC (33). In individuals with advanced lung cancer, higher circulating OPN levels were associated with a poorer prognosis and worse therapeutic responses (34-36). Prior to this study, BALF and urine OPN levels had not been assessed. Our findings revealed that OPN was upregulated in the plasma and BALF of patients with LUSC compared with those of healthy controls, but it was downregulated in the urine of patients with LUSC compared with that of healthy controls. In addition to tissue and blood, the levels of OPN in BALF and urine might also serve as a potential marker of lung squamous cell carcinoma.

AAT is a serine protease inhibitor that, while mainly produced by the liver, can also be found in other tissues and can be produced by cancer cells. Elevated AAT levels have been reported in patients with lung cancer $(12,37)$, with higher plasma AAT levels being detected in these patients $(14,38,39)$. AAT plays essential roles in the migration and invasion of cancer cells, regulating the assembly of fibronectin in the area surrounding a cell $(13,40)$. The C-terminal portions of AAT were able to induce cell proliferation and invasion in human pancreatic adenocarcinoma (41), melanoma (42) and breast carcinoma (43). When AAT expression was reduced in a human or murine model, this led to a reduction in the observed proliferative, metastatic, and adhesive behavior of these tumor cells (37). AAT deficiency has been reported to increase the risk of lung cancer (44), and tumors positive for AAT had a poorer prognosis than those that were negative for this protein (45). In the present study, AAT protein levels were increased in LUSC tumor samples, suggesting that this protein might play a role in oncogenesis. Our results demonstrated that AAT levels in the plasma, BALF and urines of patients with LUSC differed from those in the normal controls. The AUC of AAT in urine was better than that in plasma and BALF, which suggested that detection of AAT in urine might be a non-invasive tool for LUSC screening.

Our findings suggest that the measurement of KNG1, OPN and AAT in body fluids, particularly in urine, represents a simple, non-invasive strategy that might be of value for LUSC diagnosis. To the best of our knowledge, this is the first study to simultaneously evaluate these three proteins in the plasma, urine and BALF of patients with LUSC.

\section{Acknowledgements}

Not applicable.

\section{Funding}

The present study was supported by the Beijing Natural Science Foundation (grantno.7172106),Beijing Municipal Administration of Hospitals' Ascent Plan (grant no. DFL20150701) and Enhancement Funding of Beijing Key Laboratory of Urinary Cellular Molecular Diagnostics (grant no. 2019-JS02).

\section{Availability of data and materials}

The datasets used and/or analyzed during the current study are available from the corresponding author on reasonable request.

\section{Authors' contributions}

MZ and WW designed the study. WW and SW performed the experiments. WW wrote the article. SW and MZ reviewed and edited the manuscript. All authors read and approved the manuscript.

\section{Ethics approval and consent to participate}

The Ethics Committee of Beijing Shijitan Hospital, Capital Medical University approved the present study. All study participants provided written informed consent, and the study was performed following the Declaration of Helsinki.

\section{Patient consent for publication}

Patients provided written informed consent for the publication of their data.

\section{Competing interests}

The authors declare that they have no competing interests. 


\section{References}

1. Siegel RL, Miller KD and Jemal A: Cancer statistics, 2019. CA Cancer J Clin 69: 7-34, 2019.

2. Osmani L, Askin F, Gabrielson E and Li QK: Current WHO guidelines and the critical role of immunohistochemical markers in the subclassification of non-small cell lung carcinoma (NSCLC): Moving from targeted therapy to immunotherapy. Semin Cancer Biol 52: 103-109, 2018.

3. Kikuchi T, Hassanein M, Amann JM, Liu Q, Slebos RJ, Rahman SM, Kaufman JM, Zhang X, Hoeksema MD, Harris BK, et al: In-depth proteomic analysis of nonsmall cell lung cancer to discover molecular targets and candidate biomarkers. Mol Cell Proteomics 11: 916-932, 2012.

4. Uribarri M, Hormaeche I, Zalacain R, Lopez-Vivanco G, Martinez A, Nagore D and Ruiz-Argüello MB: A new biomarker panel in bronchoalveolar lavage for an improved lung cancer diagnosis. J Thorac Oncol 9: 1504-1512, 2014.

5. Shimura T, Iwasaki H, Kitagawa M, Ebi M, Yamada T, Yamada T, Katano T, Nisie H, Okamoto Y, Ozeki K, et al: Urinary cysteine-rich protein 61 and trefoil factor 3 as diagnostic biomarkers for colorectal cancer. Transl Oncol 12: 539-544, 2019

6. Ahn JM, Sung HJ, Yoon YH, Kim BG, Yang WS, Lee C, Park HM, Kim BJ, Kim BG, Lee SY, et al: Integrated glycoproteomics demonstrates fucosylated serum paraoxonase 1 alterations in small cell lung cancer. Mol Cell Proteomics 13: $30-48,2014$

7. Abdullah-Soheimi SS, Lim BK, Hashim OH and Shuib AS Patients with ovarian carcinoma excrete different altered levels of urine CD59, kininogen-1 and fragments of inter-alpha-trypsin inhibitor heavy chain $\mathrm{H} 4$ and albumin. Proteome Sci 8: 58, 2010.

8. Yu JS, Chen YT, Chiang WF, Hsiao YC, Chu LJ, See LC, Wu CS, Tu HT, Chen HW, Chen CC, et al: Saliva protein biomarkers to detect oral squamous cell carcinoma in a high-risk population in Taiwan. Proc Natl Acad Sci USA 113: 11549-11554, 2016

9. Wang J, Wang X, Lin S, Chen C, Wang C, Ma Q and Jiang B: Identification of kininogen-1 as a serum biomarker for the early detection of advanced colorectal adenoma and colorectal cancer. PLoS One 8: e70519, 2013.

10. Briones-Orta MA, Avendaño-Vázquez SE, Aparicio-Bautista DI, Coombes JD, Weber GF and Syn WK: Osteopontin splice variants and polymorphisms in cancer progression and prognosis. Biochim Biophys Acta Rev Cancer 1868: 93-108A, 2017.

11. Zhao H, Chen Q, Alam A, Cui J, Suen KC, Soo AP, Eguchi S, $\mathrm{Gu} \mathrm{J}$ and Ma D: The role of osteopontin in the progression of solid organ tumour. Cell Death Dis 9: 356, 2018.

12. Wang W, Wang S and Zhang M: Identification of urine biomarkers associated with lung adenocarcinoma. Oncotarget 8 : 38517-38529, 2017

13. Li Y, Miao L, Yu M, Shi M, Wang Y, Yang J, Xiao Y and Cai $\mathrm{H}$ : $\alpha 1$-antitrypsin promotes lung adenocarcinoma metastasis through upregulating fibronectin expression. Int J Oncol 50 : 1955-1964, 2017

14. Liang Y, Ma T, Thakur A, Yu H, Gao L, Shi P, Li X, Ren H, Jia L, Zhang S, et al: Differentially expressed glycosylated patterns of alpha-1-antitrypsin as serum biomarkers for the diagnosis of lung cancer. Glycobiology 25: 331-340, 2015.

15. Yu S, Meng Q, Hu H and Zhang M: Correlation of ANXA1 expression with drug resistance and relapse in bladder cancer. Int J Clin Exp Pathol 7: 5538-5548, 2014.

16. Pastor MD, Nogal A, Molina-Pinelo S, Quintanal-Villalonga Á, Meléndez R, Ferrer I, Romero-Romero B, De Miguel MJ, López-Campos JL, Corral J, et al: IL-11 and CCL-1: Novel protein diagnostic biomarkers of lung adenocarcinoma in bronchoalveolar lavage fluid (BALF). J Thorac Oncol 11: 2183-2192, 2016.

17. Doustjalali SR, Yusof R, Yip CH, Looi LM, Pillay B and Hashim OH: Aberrant expression of acute-phase reactant proteins in sera and breast lesions of patients with malignant and benign breast tumors. Electrophoresis 25: 2392-2401, 2004

18. Abdul-Rahman PS, Lim BK and Hashim OH: Expression of high-abundance proteins in sera of patients with endometrial and cervical cancers: Analysis using 2-DE with silver staining and lectin detection methods. Electrophoresis 28: 1989-1996, 2007.

19. $\mathrm{Mu} \mathrm{AK}$, Lim BK, Hashim OH and Shuib AS: Identification of $\mathrm{O}$-glycosylated proteins that are aberrantly excreted in the urine of patients with early stage ovarian cancer. International journal of molecular sciences 14: 7923-7931, 2013.
20. Sandim V, Pereira Dde A, Kalume DE, Oliveira-Carvalho AL, Ornellas AA, Soares MR, Alves G and Zingali RB: Proteomic analysis reveals differentially secreted proteins in the urine from patients with clear cell renal cell carcinoma. Urol Oncol 34: 5.e11-25, 2016.

21. Xu J, Fang J, Cheng Z, Fan L, Hu W, Zhou F and Shen H: Overexpression of the Kininogen-1 inhibits proliferation and induces apoptosis of glioma cells. J Exp Clin Cancer Res 37: 180, 2018.

22. Schrödter S, Braun M, Syring I, Klümper N, Deng M, Schmidt D, Perner S, Müller SC and Ellinger J: Identification of the dopamine transporter SLC6A3 as a biomarker for patients with renal cell carcinoma. Mol Cancer 15: 10, 2016.

23. Jiang W, Zhang L, Guo Q, Wang H, Ma M, Sun J and Chen C: Identification of the pathogenic biomarkers for hepatocellular carcinoma based on RNA-seq analyses. Pathol Oncol Res 25: 1207-1213, 2019.

24. Liu W, Liu B, Cai Q, Li J, Chen X and Zhu Z: Proteomic identification of serum biomarkers for gastric cancer using multi-dimensional liquid chromatography and 2D differential gel electrophoresis. Clinica Chimica Acta 413: 1098-1106, 2012.

25. Quesada-Calvo F, Massot C, Bertrand V, Longuespée R, Blétard N, Somja J, Mazzucchelli G, Smargiasso N, Baiwir D, De Pauw-Gillet MC, et al: OLFM4, KNG1 and Sec24C identified by proteomics and immunohistochemistry as potential markers of early colorectal cancer stages. Clin Proteomics 14: 9, 2017.

26. Gao B, Yu T, Xue D, Sun B, Shao Q, Choudhry H, Marcus V, Ragoussis J, Zhang Y, Zhang W and Gao ZH: A multidimensional integration analysis reveals potential bridging targets in the process of colorectal cancer liver metastasis. PLoS One 12: $\mathrm{e} 0178760,2017$.

27. Navaneethan U, Lourdusamy V, Gk Venkatesh P, Willard B, Sanaka MR and Parsi MA: Bile proteomics for differentiation of malignant from benign biliary strictures: A pilot study. Gastroenterol Rep 3: 136-143, 2015.

28. Li S, Yang R, Sun X, Miao S, Lu T, Wang Y, Wo Y and Jiao W: Identification of SPP1 as a promising biomarker to predict clinical outcome of lung adenocarcinoma individuals. Gene 679: 398-404, 2018.

29. Lin Q, Guo L, Lin G, Chen Z, Chen T, Lin J, Zhang B and $\mathrm{Gu} \mathrm{X}$ : Clinical and prognostic significance of OPN and VEGF expression in patients with non-small-cell lung cancer. Cancer Epidemiol 39: 539-544, 2015.

30. Kothari AN, Arffa ML, Chang V, Blackwell RH, Syn WK, Zhang J, Mi Z and Kuo PC: Osteopontin-a master regulator of epithelial-mesenchymal transition. J Clin Med 5: E39, 2016.

31. Zou C, Luo Q, Qin J, Shi Y, Yang L, Ju B and Song G: Osteopontin promotes mesenchymal stem cell migration and lessens cell stiffness via integrin $\beta 1$, FAK, and ERK pathways. Cell Biochem Biophys 65: 455-462, 2013.

32. Marotta LL, Almendro V, Marusyk A, Shipitsin M, Schemme J, Walker SR, Bloushtain-Qimron N, Kim JJ, Choudhury SA, Maruyama R, et al: The JAK2/STAT3 signaling pathway is required for growth of $\mathrm{CD} 44^{+} \mathrm{CD} 24^{-}$stem cell-like breast cancer cells in human tumors. J Clin Invest 121: 2723-2735, 2011.

33. Rouanne M, Adam J, Goubar A, Robin A, Ohana C, Louvet E, Cormier J, Mercier O, Dorfmüller P, Fattal S, et al: Osteopontin and thrombospondin-1 play opposite roles in promoting tumor aggressiveness of primary resected non-small cell lung cancer. BMC Cancer 16: 483, 2016.

34. Ostheimer C, Schweyer F, Reese T, Bache M and Vordermark D The relationship between tumor volume changes and serial plasma osteopontin detection during radical radiotherapy of non-small-cell lung cancer. Oncol Lett 12: 3449-3456, 2016.

35. Wang Y, Yang J, Liu H, Bi JR, Liu Y, Chen YY, Cao JY and $\mathrm{Lu}$ YJ: The association between osteopontin and survival in non-small-cell lung cancer patients: A meta-analysis of 13 cohorts. Onco Targets Ther 8: 3513-3521, 2015.

36. Mack PC, Redman MW, Chansky K, Williamson SK, Farneth NC, Lara PN Jr, Franklin WA, Le QT, Crowley JJ and Gandara DR; SWOG: Lower osteopontin plasma levels are associated with superior outcomes in advanced non-small-cell lung cancer patients receiving platinum-based chemotherapy: SWOG Study S0003. J Clin Oncol 26: 4771-4776, 2008.

37. Chang SH, Cho KC, Yu KN, Hong SH, Park S, Lee AY, Kim S, Lee S, Kang JW, Chae C, et al: Alpha 1-antitrypsin activates lung cancer cell survival by acting on cap-dependent protein translation, vesicle-mediated transport, and metastasis. Oncotarget 2016. 
38. Rodríguez-Piñeiro AM, Blanco-Prieto S, Sánchez-Otero N, Rodríguez-Berrocal FJ and de la Cadena MP: On the identification of biomarkers for non-small cell lung cancer in serum and pleural effusion. J Proteomics 73: 1511-1522, 2010.

39. El-Akawi ZJ, Abu-Awad AM, Sharara AM and Khader Y: The importance of alpha-1 antitrypsin (alpha1-AT) and neopterin serum levels in the evaluation of non-small cell lung and prostate cancer patients. Neuro Endocrinol Lett 31: 113-116, 2010.

40. Chang YH, Lee SH, Liao IC, Huang SH, Cheng HC and Liao PC: Secretomic analysis identifies alpha-1 antitrypsin (A1AT) as a required protein in cancer cell migration, invasion, and pericellular fibronectin assembly for facilitating lung colonization of lung adenocarcinoma cells. Mol Cell Proteomics 11: 1320-1339, 2012.

41. Kataoka H, Uchino H, Iwamura T, Seiki M, Nabeshima K and Koono M: Enhanced tumor growth and invasiveness in vivo by a carboxyl-terminal fragment of alpha1-proteinase inhibitor generated by matrix metalloproteinases: A possible modulatory role in natural killer cytotoxicity. Am J Pathol 154: 457-468, 1999.

42. Zelvyte I, Sjögren HO and Janciauskiene S: Effects of native and cleaved forms of alpha1-antitrypsin on ME 1477 tumor cell functional activity. Cancer Detect Prev 26: 256-265, 2002.
43. Zelvyte I, Lindgren S and Janciauskiene S: Multiple effects of alpha1-antitrypsin on breast carcinoma MDA-MB 468 cell growth and invasiveness. Eur J Cancer Prev 12: 117-124, 2003.

44. Yang P, Sun Z, Krowka MJ, Aubry MC, Bamlet WR, Wampfler JA, Thibodeau SN, Katzmann JA, Allen MS, Midthun DE, et al: Alpha1-antitrypsin deficiency carriers, tobacco smoke, chronic obstructive pulmonary disease, and lung cancer risk. Arch Intern Med 168: 1097-1103, 2008.

45. Higashiyama M, Doi O, Kodama K, Yokouchi H and Tateishi R: An evaluation of the prognostic significance of alpha-1-antitrypsin expression in adenocarcinomas of the lung: An immunohistochemical analysis. Br J Cancer 65: 300-302, 1992.

(i) 9 This work is licensed under a Creative Common Attribution-NonCommercial-NoDerivatives 4.0 International (CC BY-NC-ND 4.0) License. 